\title{
Valvoplasty for abnormalities of posterior (mural) cusp of the mitral valve
}

A. H. BR OWN, M. V. BRAIMBRIDGE, A. J. CLEMENT, E. SABAR, AND D. MENDEL

From the Cardio-thoracic Unit, St. Thomas' Hospital, London, S.E.1

\begin{abstract}
Five patients with abnormalities of the chordae tendineae of the posterior (mural) cusp of the mitral valve have been treated by plication of the cusp, annulus, and atrium in continuity (modified McGoon valvoplasty). They had acute symptoms with physical signs characterized by sinus rhythm and an apical pansystolic murmur radiating to the base of the heart. Investigation showed high left atrial systolic pressures in small atria. Apart from one patient who died of cerebral air embolism with a good haemodynamic result, all were immediately improved and had smooth post-operative courses. Improvement was maintained at follow-up without embolic complications despite stopping anticoagulants.
\end{abstract}

Pathological abnormalities of the chordae tendineae of the mitral valve are being diagnosed with increasing frequency and accuracy (Gerbode, Kerth, Kelly, and Selzer, 1966 ; Raftery, Oakley, and Goodwin, 1966) and account for many of the cases of mitral incompetence coming to surgery (Morris, Penner, and Brandt, 1964). An inclusive term for abnormalities of the chordae tendineae and papillary muscles, as distinct from disorders of the cusps, is not yet agreed although 'subvalvar incompetence' has been proposed by Goodwin (Raftery et al., 1966). This term is ambiguous because the chordae and papillary muscles are part of the valve mechanism, but a better term has not yet been proposed.

The anatomical disturbances of these 'subvalvar' structures that cause mitral incompetence are of three types-rupture of the chordae tendineae, attenuated chordae with redundant cusps, and dysfunction of the papillary muscles. Rupture of the chordae tendineae is usually 'idiopathic' but may be associated with rheumatic fever, bacterial endocarditis, and disorders of connective tissue such as the Ehlers-Danlos syndrome (Sanders, Austen, Harthorne, Dinsmore, and Scannell, 1967). Attenuated chordae with large redundant cusps comprise a clinical syndrome which may result in mitral incompetence, particularly if the thin chordae rupture (Edwards and Burchell, 1958 ; Berghuis, Kirklin, Edwards, and Titus, 1964 ; Gerein, Gourlay, and Kavanagh-Gray,
1965 ; Barlow and Bosman, 1966; Stannard, Sloman, Hare, and Goble, 1967). Dysfunction of papillary muscles is usually a sequel of posterior myocardial infarction.

Either or both cusps of the mitral valve may be affected by abnormalities of the chordae and papillary muscles. This communication is confined to chordal abnormalities affecting the posterior (mural) cusp and specifically excludes disorders of the anterior (aortic) cusp or the papillary muscles. Its object is to demonstrate that a modified McGoon valvoplasty (McGoon, 1960) is both safe and effective in this specific instance and avoids the long-term complications of artificial valve replacement which has been recommended as the standard treatment of the condition (Sanders et al., 1967).

Mitral incompetence due to 'subvalvar' abnor- 을 malities differs from that due to rheumatic fever $N$ in several ways. The patient is older and the onset of symptoms is sudden and severe because of the abrupt onset of marked incompetence into a small left atrium. The flail segment of posterior cusp forms a hood which directs the incompetent jet 0

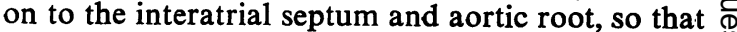
the apical pansystolic murmur radiates to the base ? of the heart, and its maximum intensity is late, 0 which may cause confusion with an aortic ejection murmur. The rhythm is usually sinus, and a giant ' $V$ ' wave in a small left atrium is shown by chest radiography at cardiac catheterization. A large, 
redundant cusp may be seen on ventricular angiography, but a flail segment devoid of chordal attachment is rarely seen.

The McGoon operation-plication of the flail cusp-was used in all our patients, with the modification of continuing the plication on to the atrial wall (Gerbode et al., 1966). Cardiopulmonary bypass was instituted through a median sternotomy using an aortic and two caval cannulae, and the left atrium was opened behind the interatrial septum (Fig. 1). The unsupported section of posterior cusp was identified (Fig. 2), and the edges of the
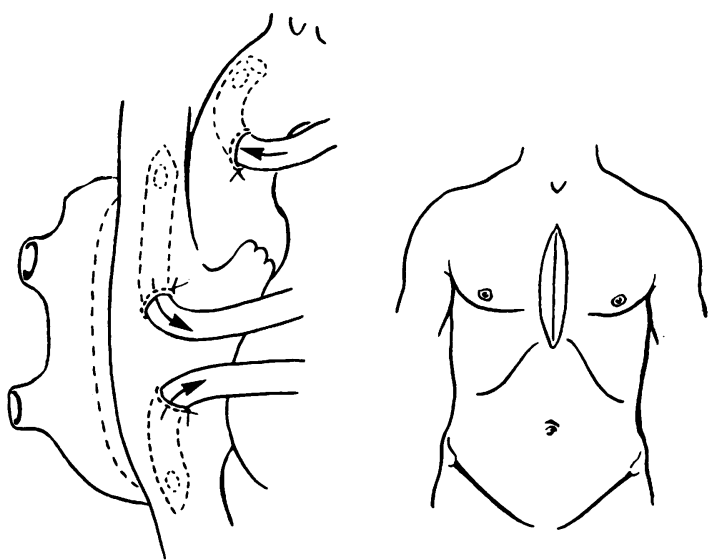

FIG. 1. Median sternotomy incision, method of cannulation with an aortic root and two atrial cannulae, and a left atrial incision continued behind the heart.

flail segment still attached to chordae tendineae were approximated with horizontal mattress sutures of 2/0 silk (Figs 3 and 4). These stitches were continued on to the atrial wall for $3 \mathrm{~cm}$. beyond the valve ring so that the flail segment, ring, and atrial wall were plicated in continuity. Interrupted 4/0 silk sutures supported the mattress sutures (Fig. 5). Air was carefully evacuated by inserting a left ventricular apical vent, the left atrium was closed, and bypass discontinued.

\section{CASE REPORTS}

The clinical features of the five patients are summarized in Table I.

PATIENT 1. W. D. This 35-year-old woman gave no history of rheumatic fever. A cardiac murmur had been heard at the age of 14 years. Dyspnoea on effort began abruptly one year before admission, and within six months she was confined to bed by congestive cardiac failure.
On clinical examination atrial fibrillation, left ventricular hypertrophy, and a palpable pulmonary second sound were found. On auscultation at the apex there were an accentuated mitral first sound, a loud pansystolic murmur (grade 3/4), a third sound, and a soft mid-diastolic murmur (Fig. 6). Electrocardiography showed right axis deviation $\left(+110^{\circ}\right)$ and left ventricular hypertrophy and strain. Moderate left atrial and ventricular enlargement were seen on chest radiography. At cardiac catheterization the right atrial pressure was a mean of $17 \mathrm{~mm}$. $\mathrm{Hg}$ with a ' $\mathrm{V}$ ' wave of $21 \mathrm{~mm} . \mathrm{Hg}$; the pulmonary artery pressure was $86 / 35 \mathrm{~mm}$. $\mathrm{Hg}$, and the pulmonary arterial wedge pressure was a mean of $26 \mathrm{~mm}$. Hg. No aortic incompetence or mitral calcification was seen on angiocardiography with injection into the aortic root.

At operation on 24 May 1966 the ruptured chordae tendineae were found to be causing severe incompetence through the centre of a flail posterior cusp. Plication of the cusp and atrial wall were performed (Figs 1 to 5) and the valve was seen to be fully competent. Following surgery, despite a good circulation, cerebral damage became apparent. It had not been realized how difficult removal of air could be in the presence of a completely competent mitral valve, a needle vent in the aortic root not having become standard practice at this stage. Functionally, the mitral valve was normal after operation, with a normal circulatory state and no murmurs. Cerebral damage proved fatal 10 days after operation.

PATIENT 2. D. R. This 52-year-old woman gave no history of rheumatic fever. Exercise tolerance had increased over seven years to become moderately severe. Clinical examination showed a malar flush, sinus rhythm, and slight left ventricular hypertrophy. On auscultation at the apex there was a loud (grade $3 / 4$ ) pansystolic murmur conduoted to the praecordium, and a fourth heart sound. A 'P mitrale' without left ventricular hypertrophy was seen on the electrocardiogram, and the chest radiograph showed slight right atrial, moderate left atrial, and marked ventricular enlargement (Fig. 7). At transseptal catheterization there was a ' $V$ ' wave of $30 \mathrm{~mm}$. $\mathrm{Hg}$ in the left atrium, and the intracardiac phonocardiogram demonstrated a left atrial pan-systolic murmur which could also be detected in the right heart near the intratrial septum (Fig. 8). Angiocardiography was not performed.

At operation on 27 October 1966 the left atrium was found to be only slightly enlarged, and there were systolic thrills within it and over the aortic root. The chordae attached to the medial half of the posterior cusp were detached, permitting systolic prolapse of a hood-shaped segment of the cusp. This was plicated with the valve ring and atrial wall in continuity, following which there was no palpable systolic thrill and the left atrial pressure fell from $60 / 11 \mathrm{~mm}$. $\mathrm{Hg}$ before surgery to $25 / 15 \mathrm{~mm}$. $\mathrm{Hg}$ afterwards. Post-operative progress was uneventful.

At follow-up one year later she was asymptomatic and in sinus rhythm. Left ventricular hypertrophy 


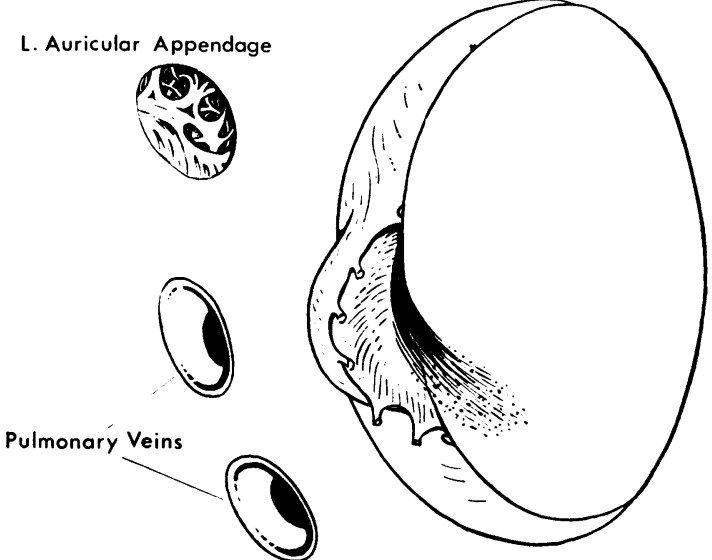

FIG. 2 Interior of left atrium. Flail segment of posterior cusp forms a hood directing the incompetent jet forwards and medially against the atrial septum.

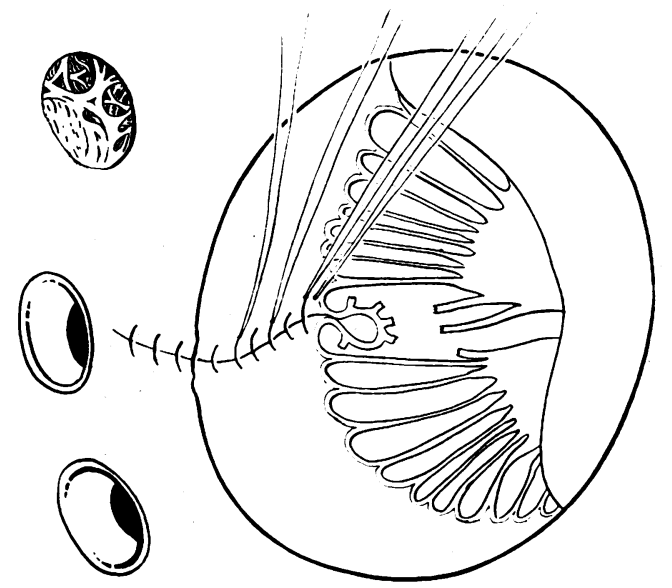

FIG. 4. The first suture pushes the flail segment underneath the cusp and makes a groove which is continued by interrupted sutures on to the atrial wall.

was less. A soft mitral pansystolic murmur was audible but no third sound. The heart size was $10 \%$ less than before operation (Fig. 9).

PATIENT 3. D. H. This 51-year-old woman gave no history of rheumatic fever. A cardiac murmur had been heard 20 years previously during an attack of bronchitis, but she was asymptomatic until a year before admission, when she had bronchopneumonia. Her exercise tolerance then increased to become severe (grade 3/4) with orthopnoea and paroxysmal nocturnal dyspnoea. Examination showed a malar flush, atrial fibrillation, a moderate left ventricular heave, and a palpable pulmonary second sound. On

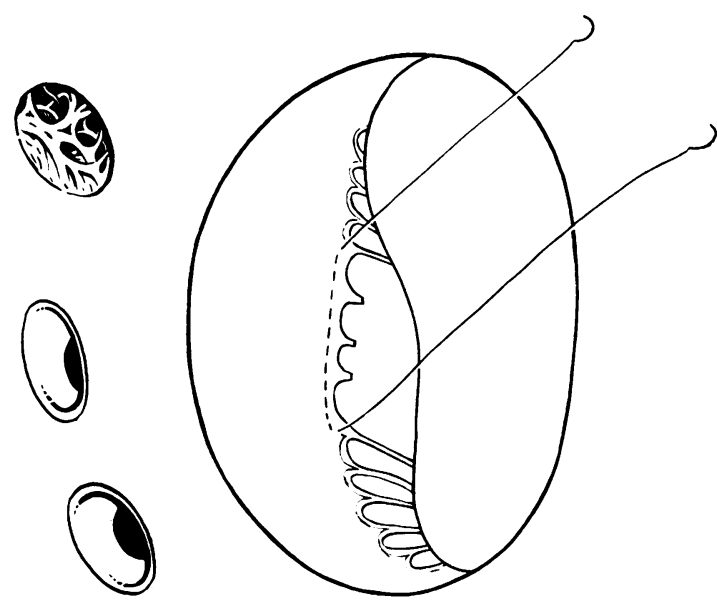

FIG. 3. The flail section of posterior cusp is obliterated by drawing together the parts of the cusp that are still supported by chordae tendineae.

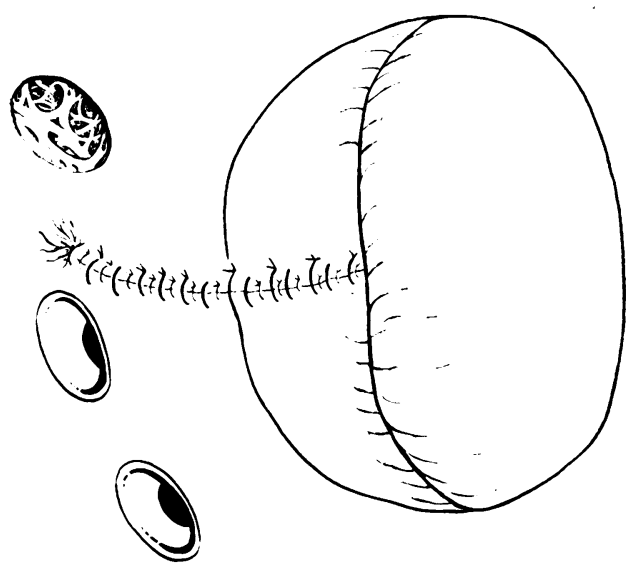

FIG. 5. The completed suture line. Continuation on to the left atrial wall plicates the mitral valve ring and supports the sutures in the cusp.

auscultation at the apex there was a loud (grade $3 / 4$ ) pansystolic murmur with a thrill radiating to the base of the heart and a third sound. The pulmonary second sound was loud. Right axis deviation $\left(+120^{\circ}\right)$ with inversion of $\mathbf{T}$ waves over the right heart was shown on electrocardiography. Moderate enlargement of the right heart and the left atrium was seen radiographically (Fig. 10). Cardiac catheterization demonstrated a pulmonary artery pressure of $55 / 14 \mathrm{~mm}$. $\mathrm{Hg}$ and a left atrial pressure of $35 / 0 \mathrm{~mm}$. Hg. Severe (grade 3/4) mitral incompetence and a ballooned mural cusp were confirmed by angiography (Fig. 11).

At operation on 30 January 1967 there was only slight left atrial enlargement. Chordae attached to the 

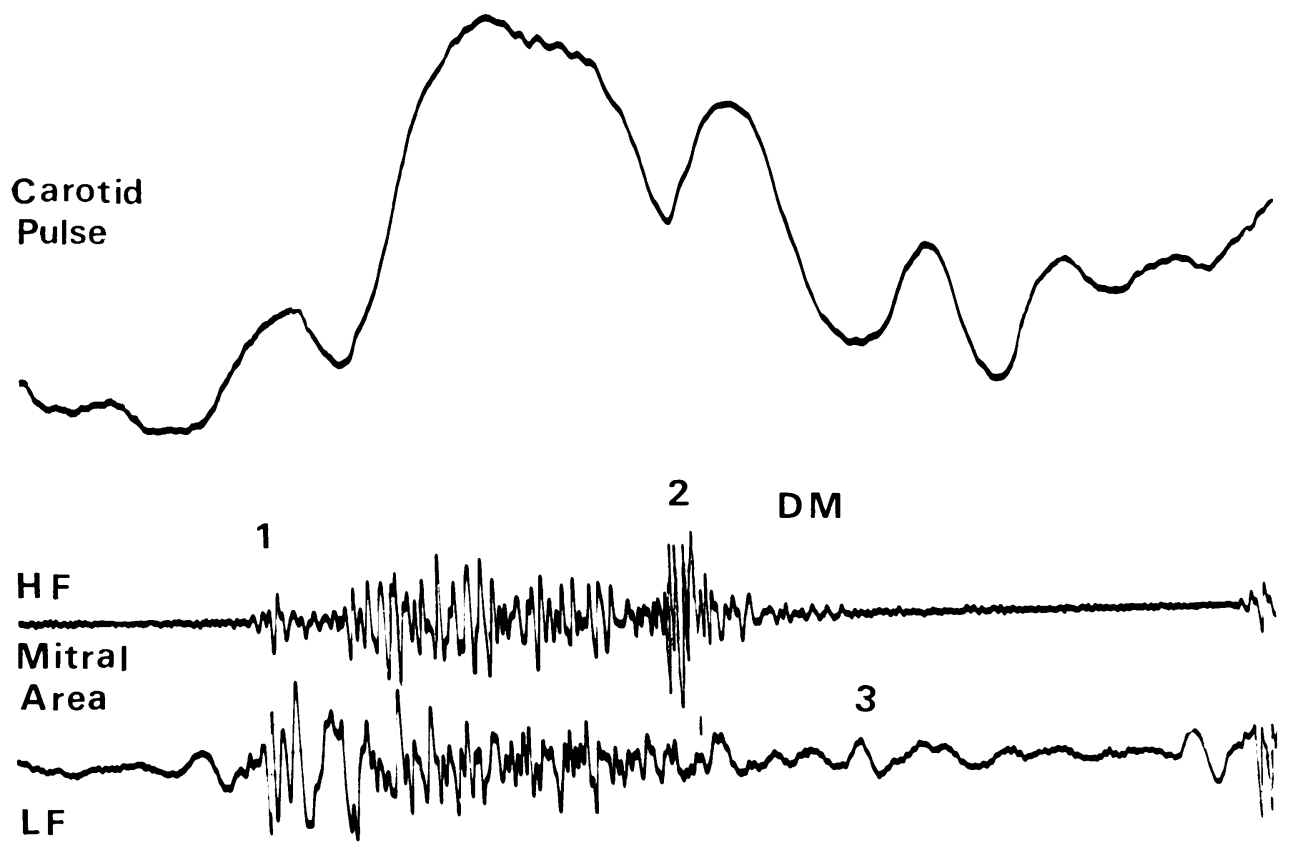

FIG. 6. Patient 1. Phonocardiogram. The pansystolic murmur tends towards a diamond shape rather than the classical square pansystolic murmur of mitral incompetence. The mid-diastolic 'flow' murmur and third sound of pure mitral incompetence are also seen.

FIG. 7. Patient 2. Chest radiograph shows slight right atrial, moderate left atrial, and ventricular enlargement.

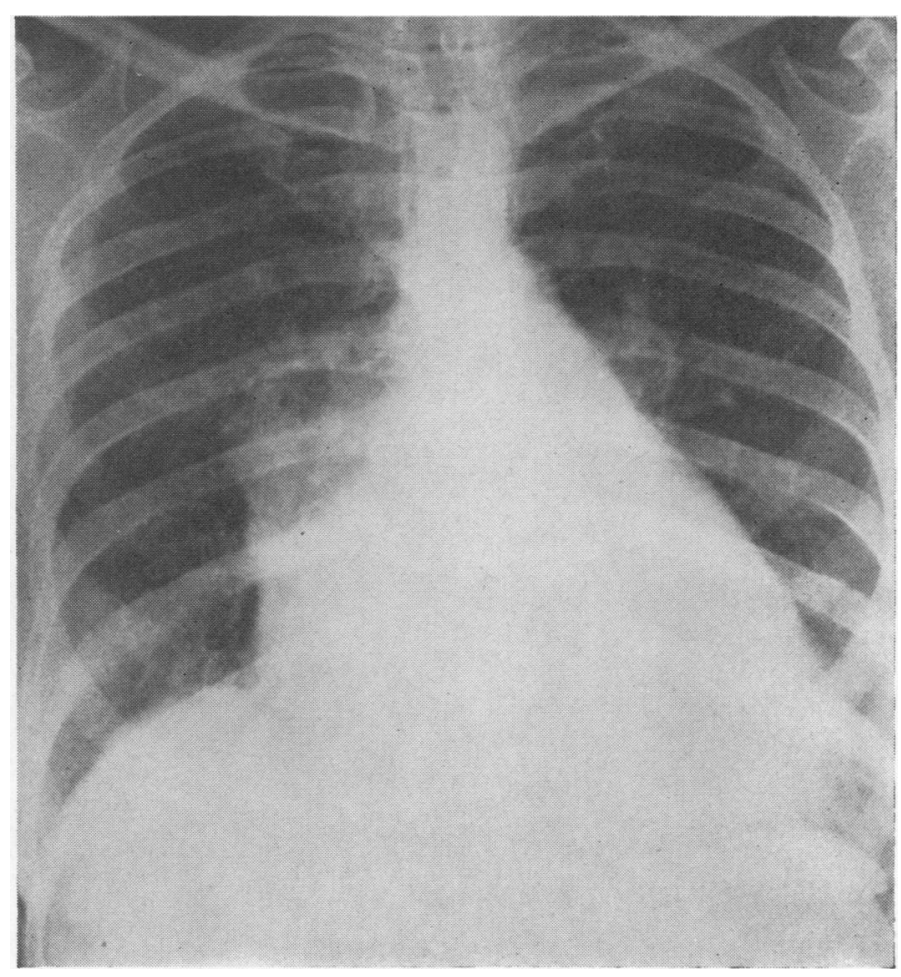




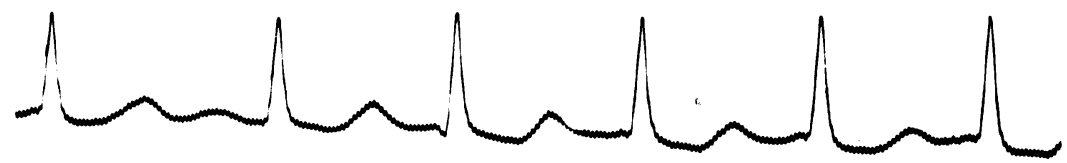

R A

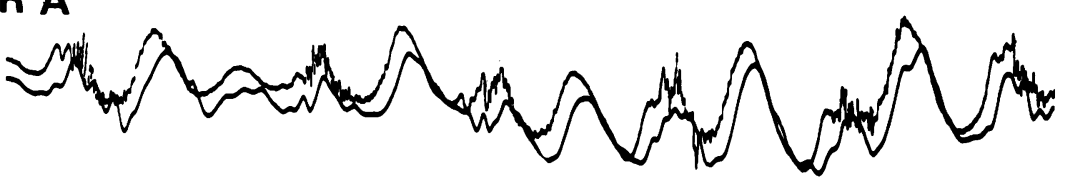

Intracardiac Phono

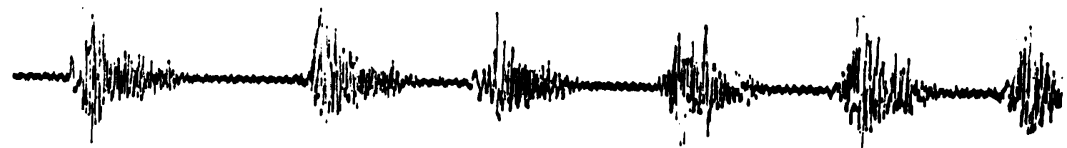

FIG. 8. Patient 2. Intracardiac phonocardiogram. Pansystolic, though rather diamond-shaped, murmur well recorded on the right side of the atrial septum.

FIG. 9. Patient 2. Chest radiograph at follow-up one year later. Comparison with Fig. 7 shows marked reduction in atrial and $D$ ventricular enlargement, the cardiothoracic ratio being reduced $N$ by $10 \%$. 


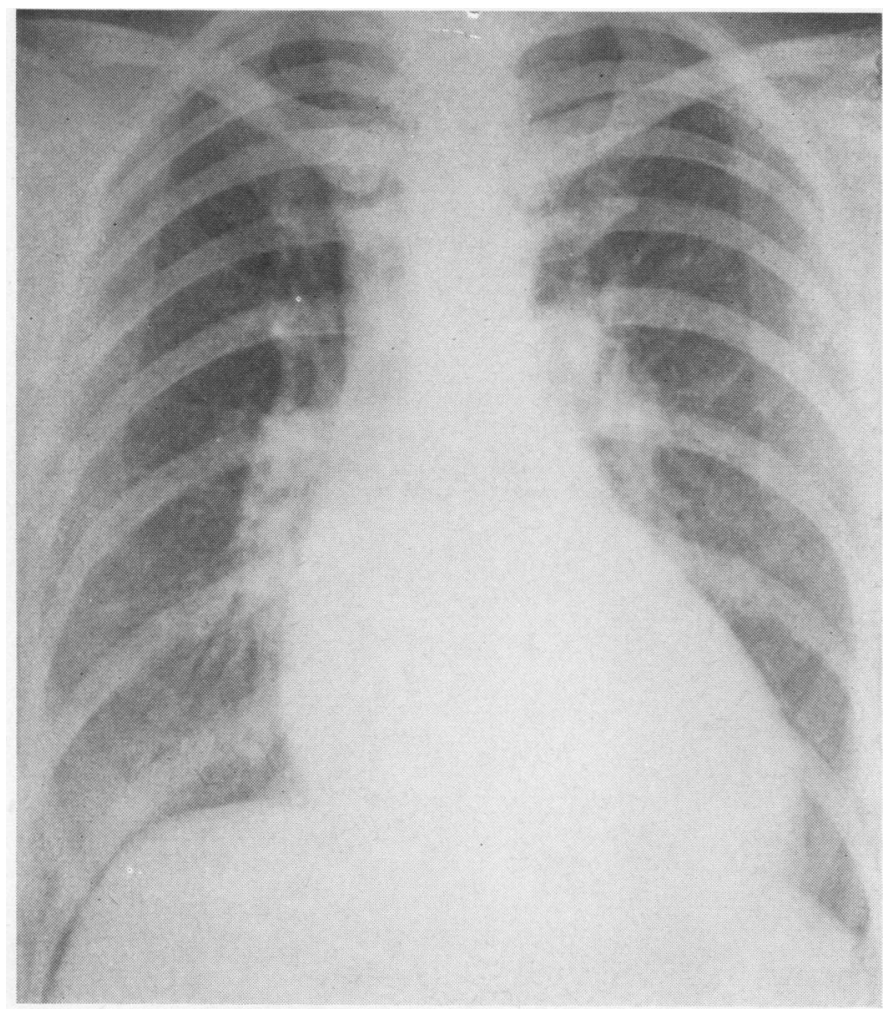

FIG. 10. Patient 3. Chest radiograph shows moderate enlargement of right and left atria and slight ventricular enlargement.

medial part of the posterior cusp had ruptured and some more lateral chordae were attenuated, resulting in the typical systolic hood-like prolapse of that segment of cusp. This, with ring and atrium, was plicated in continuity, abolishing the incompetence. Recovery was uneventful. Eight months later she was asymptomatic, in sinus rhythm after D.C. cardioversion, and her heart was $9 \%$ smaller with normal heart sounds (Fig. 12).

Patient 4. F. G. This man, aged 54, had no history of rheumatic fever. Precordial pain, syncope, and pulmonary oedema began suddenly two years before admission, after which he was severely (grade 4/4) dyspnoeic, with orthopnoea, paroxysmal nocturnal dyspnoea, and slight ankle oedema. On examination he was cachectic, with digital clubbing and a malar flush. His jugular venous pressure was raised, and he had moderate left ventricular hypertrophy and a palpable mitral first sound. On auscultation at the apex there was a loud (grade 3/4) pansystolic murmur radiating to the base of the heart, a third sound, and a soft mid-diastolic murmur. Rales and rhonchi were audible over the base of the lungs. Electrocardiography showed left atrial hypertrophy, a mean frontal QRS axis of $0^{\circ}$, and inversion of $T$ waves in lead II. Moderate left atrial and ventricular

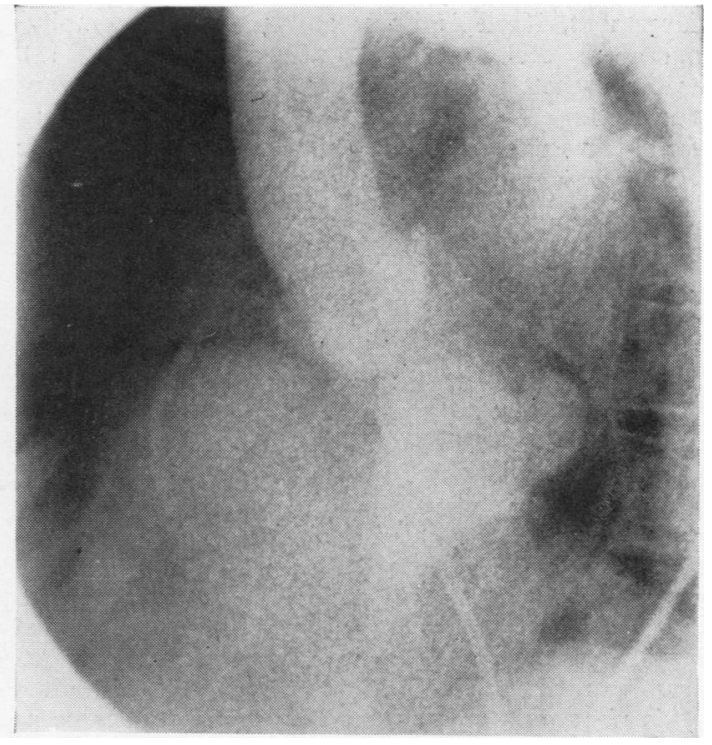

FIG. 11. Patient 3. Left ventricular angiogram. The balloon posterior (mural) cusp is seen projecting backwards into the left atrium. 


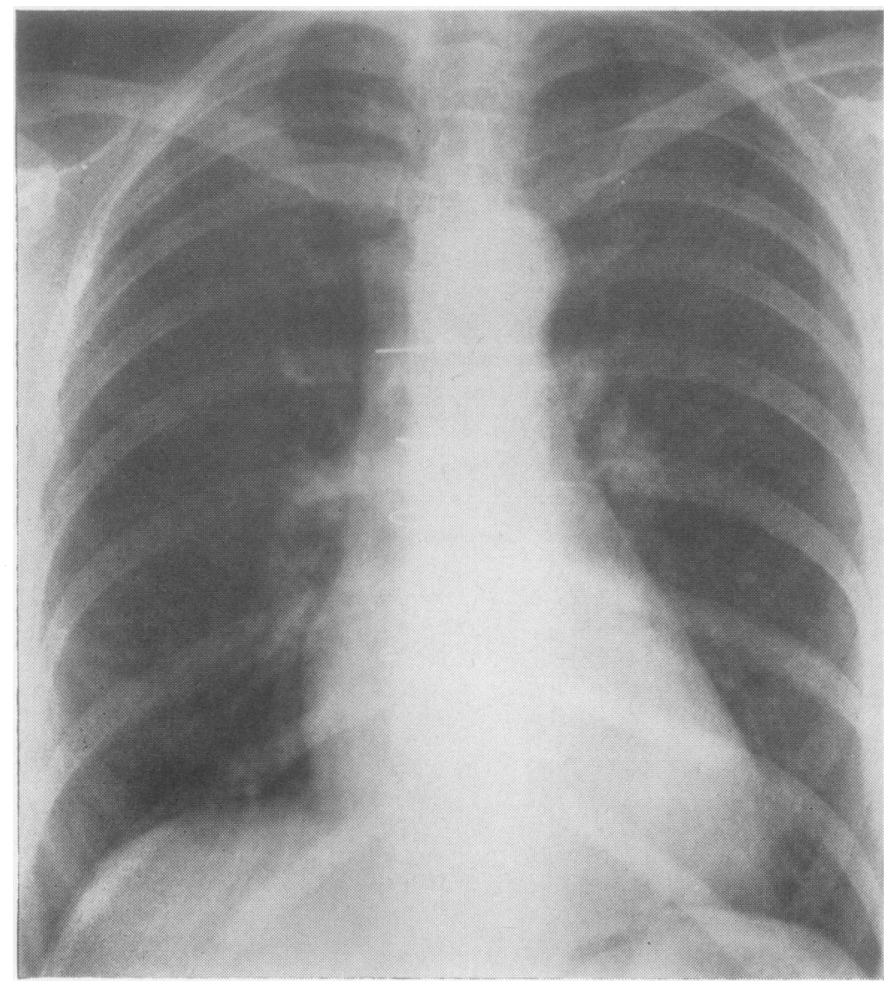

FIG. 12. Patient 3. Post-operative chest radiograph. Reduction in size of atria and ventricle with the cardiothoracic ratio smaller by $9 \%$.

enlargement, Kerley's lines, and pulmonary emphysema were seen on chest radiography (Fig. 13). Cardiac catheterization demonstrated a ' $V$ ' wave of $60 \mathrm{~mm}$. $\mathrm{Hg}$ in the left atrium and a pulmonary arterial pressure of $75 / 30 \mathrm{~mm}$. Hg. A pansystolic murmur was detected in the left atrium (Fig. 14) and in the right atrium near a patent foramen ovale by intracardiac phonocardiography (Fig. 15). The left ventricular end diastolic pressure was raised and the arterial oxygen saturation was only $80 \%$. Angiocardiography was not performed.

Operation was performed on 14 February 1967. On palpation of the right atrium, the jet of mitral incompetence was palpable, impinging on the interatrial septum, on the left side of which there was a $1 \mathrm{~cm}$. diameter calcified plaque: The central chordae of the posterior cusp had ruptured, resulting in systolic prolapse of a 'hood' of cusp. This was plicated in the usual way, with disappearance of the incompetent jet. Because of his chronic bronchitis he required assisted ventilation for six days but had no other postoperative problem. Nine months later he was limited by his poor pulmonary reserve to the same degree as he had been before the acute cardiac symptoms began. The heart sounds were normal, but there were still added sounds in the lungs. Chest radiography showed the heart to be $10 \%$ smaller (Fig. 16).
PATIENT 5. A.E. This 57-year-old woman had a history of fever at the age of 21 and 27, diagnosed as rheumatic because of heart murmurs, after which she had refrained from more than the gentlest activity. Diuretics were begun one year before admission because of the onset of orthopnoea. On clinical examination she was in sinus rhythm with marked left ventricular hypertrophy and a palpable third sound. At the apex there was a loud (grade 4/4) pansystolic murmur radiating to the base of the heart, and a loud third sound. Electrocardiography confirmed sinus rhythm and showed a $P$ mitrale, a mean frontal QRS axis of $0^{\circ}$, and left ventricular hypertrophy and strain. Moderate enlargement of the left atrium and ventricle were seen on chest radiography (Fig. 17). Cardiac catheterization showed a left ventricular enddiastolic pressure of $3-6 \mathrm{~mm}$. $\mathrm{Hg}$, but the left atrium was not entered. Severe (grade 3/4) mitral incompetence with a redundant posterior cusp prolapsing into the left atrium was shown on left ventricular angiography (Fig. 18).

At operation on 27 July 1967 the left atrium was moderately large and a systolic thrill could be felt impinging on the interatrial septum. The posterior cusp of the mitral valve was redundant with stretched, but not ruptured, central chordae producing severe incompetence. Extensive plication of the prolapsing 


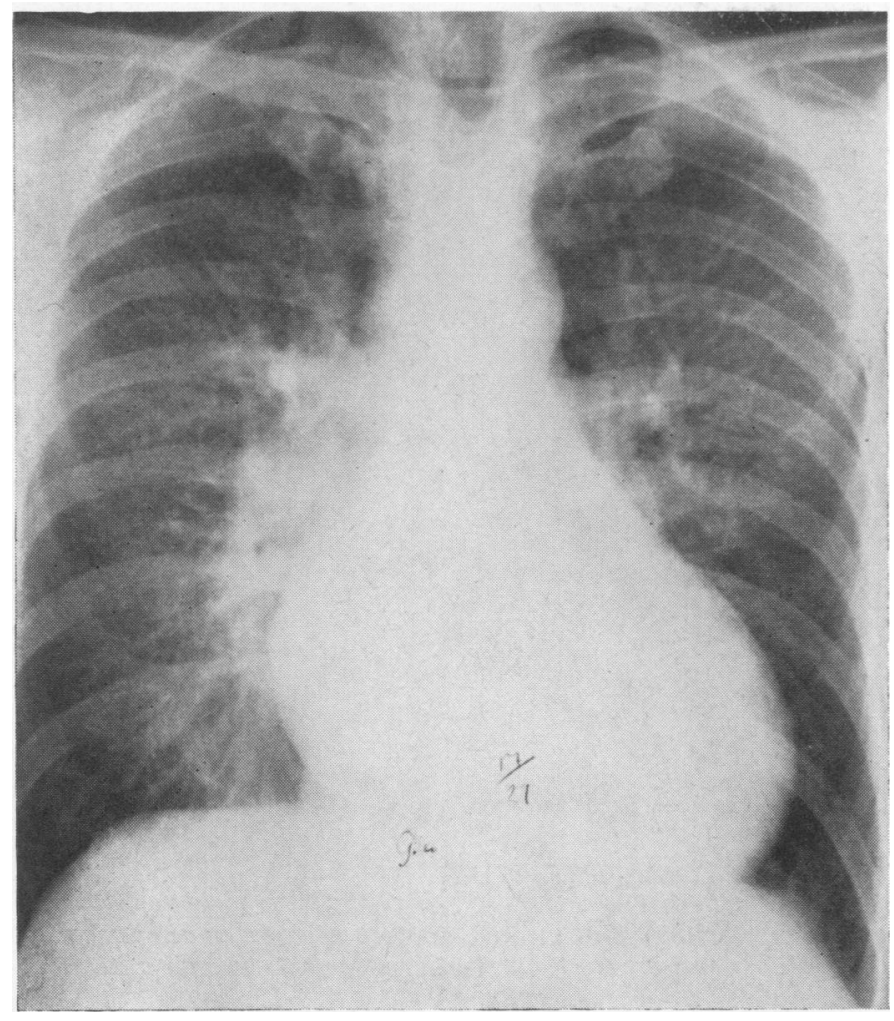

FIG. 13. Patient 4. Chest radiograph. Moderate left atrial and ventricular enlargement with Kerley's lines (the last not being easily visible on photographic reproduction).

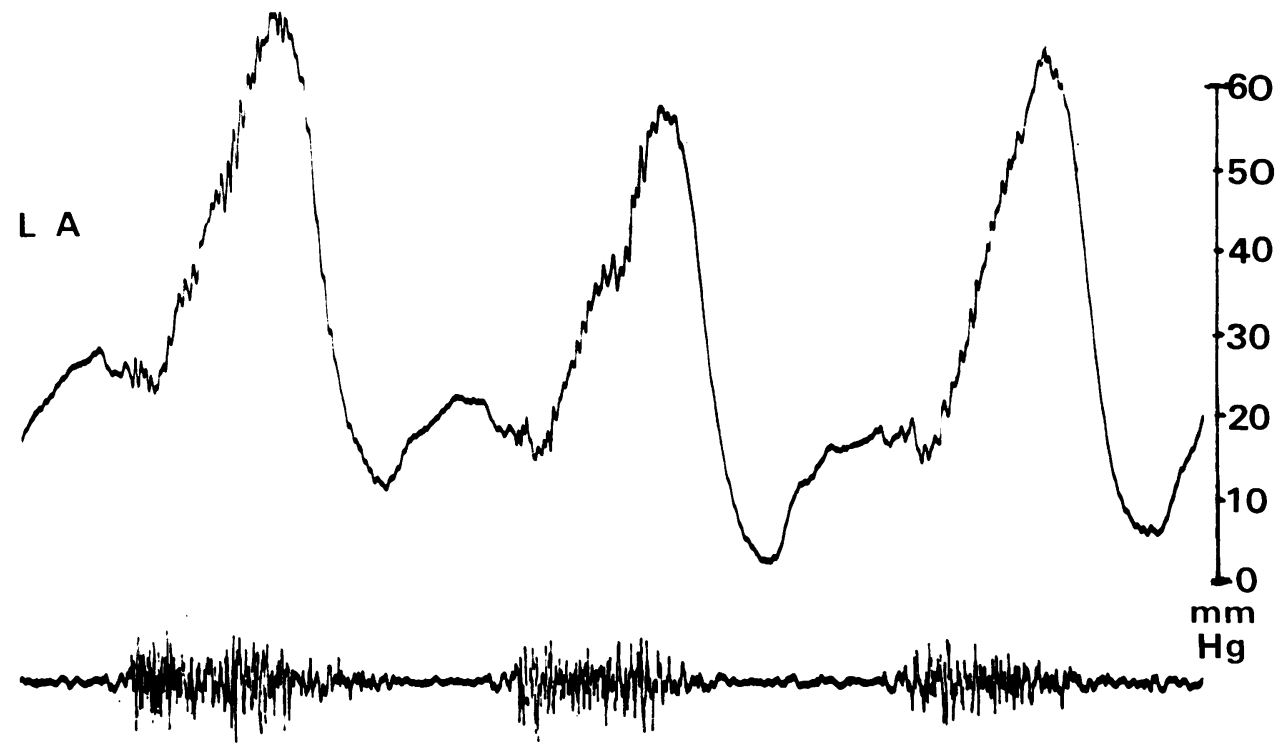

\section{Phono}

FIG. 14. Patient 4. Left atrial pressure and intracardiac phonocardiogram. The ' $V$ ' wave is $60 \mathrm{~mm} . \mathrm{Hg}$ and the pansystolic murmur is seen in the left atrium. 

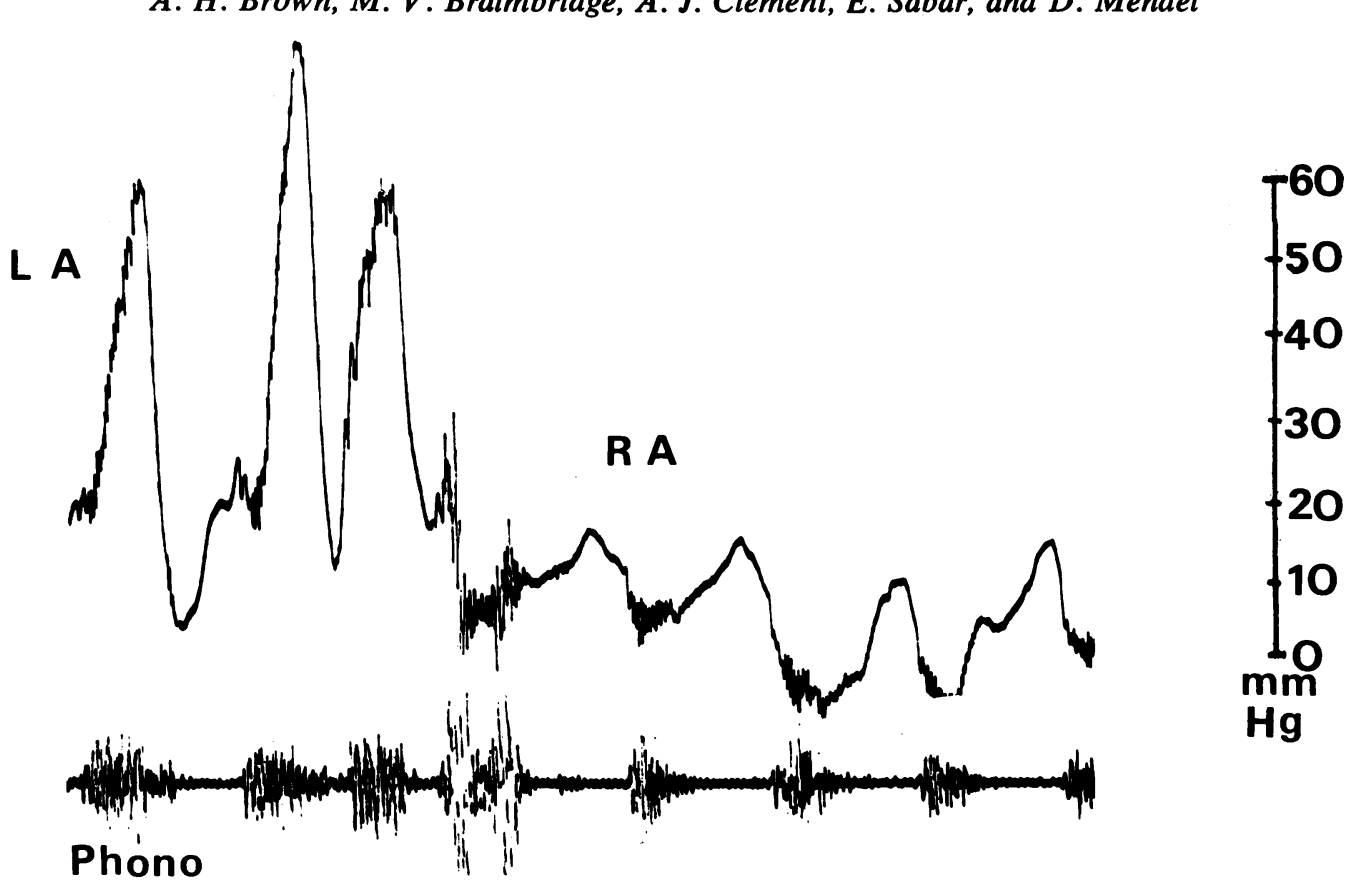

FIG. 15. Patient 4. Intracardiac phonocardiogram. Withdrawal of the end catheter manometer across the atrial septum shows the systolic murmur still recorded on pressure trace and phonocardiogram in the right atrium.

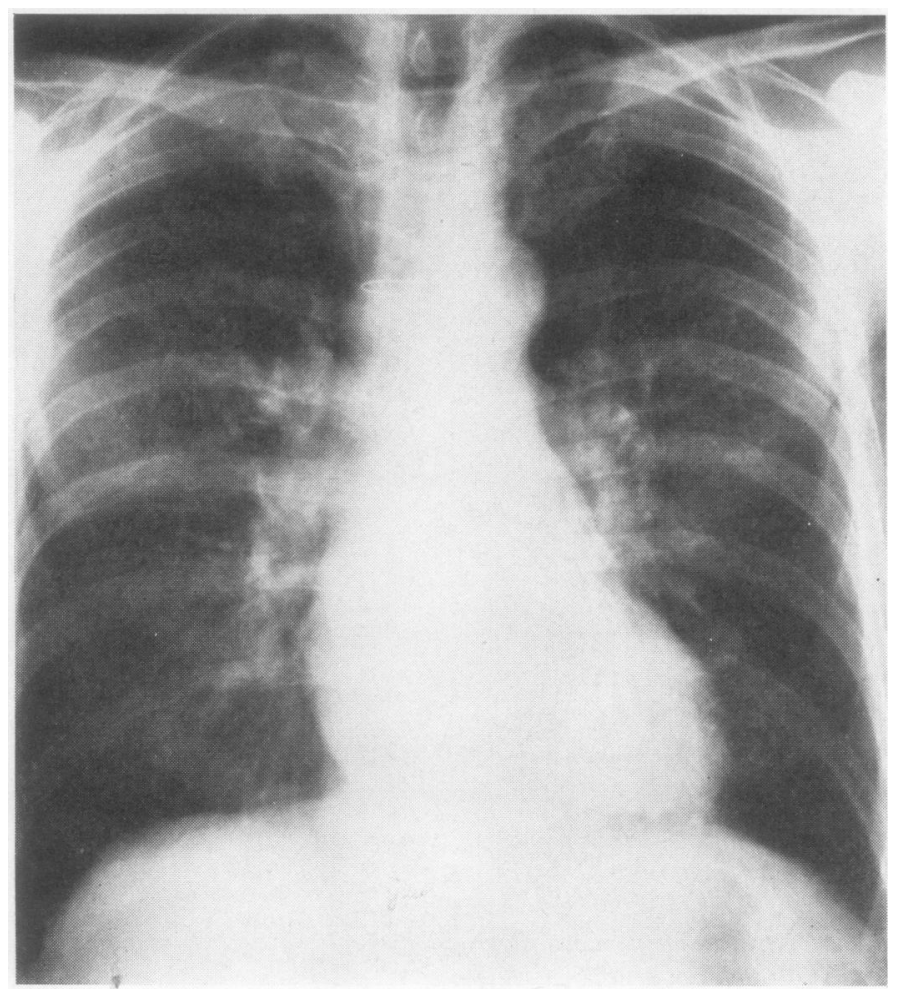

FIG. 16. Patient 4. Post-operative chest radiograph showing reduction in cardiac을 size. 


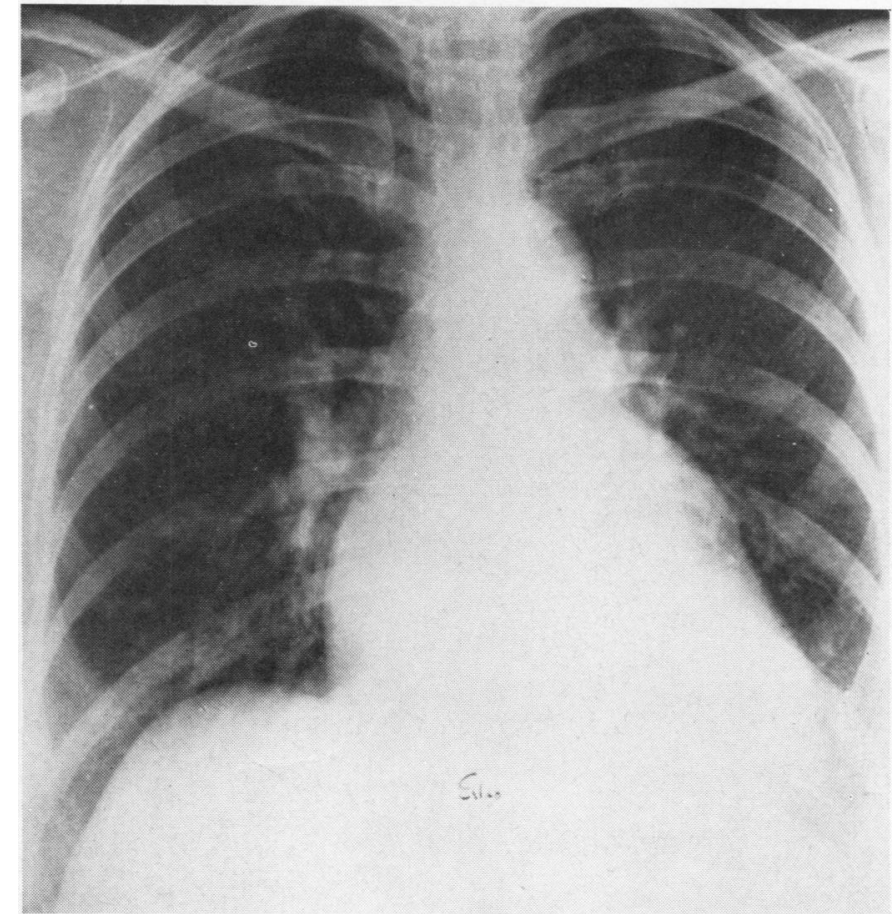

FIG. 17. Patient 5. Pre-operative chest radiograph shows moderate enlargement of the left atrium and ventricle.

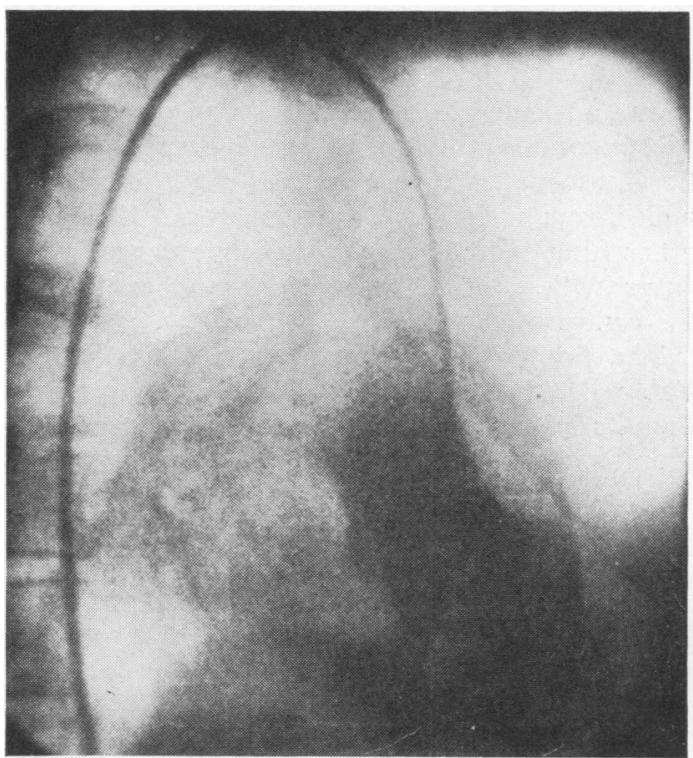

FIG. 18. Patient 5. Left ventricular angiogram. The redundant posterior cusp is seen to prolapse into the left atrium. segment, with annular and atrial support, resulted in a totally competent valve. At follow-up six months later she was asymptomatic. Initially, the heart sounded normal, but with increasing activity a late systolic murmur has become audible. Chest radiography showed the heart to be $11.5 \%$ smaller (Fig. 19).

\section{SUMMARY OF CASE REPORTS}

The pre-operative details of the patients with abnormalities of chordae of the posterior (mural) cusp of the mitral valve are summarized in Table I. Their average age was 55 years. Disablement was severe and of rapid onset in all but the patient who had severely curtailed her activities because of the presence of a heart murmur. Three presented in sinus rhythm, and the systolic murmur radiated to the base of the heart in four. None had marked enlargement of the heart on chest radiography. Giant left atrial ' $V$ ' waves or high pulmonary wedge pressures were measured in four patients, while in patient 5 the decision to operate was made on the angiographic evidence of gross mitral incompetence with a flail posterior cusp. In no other case did the angiocardiogram influence this decision. 


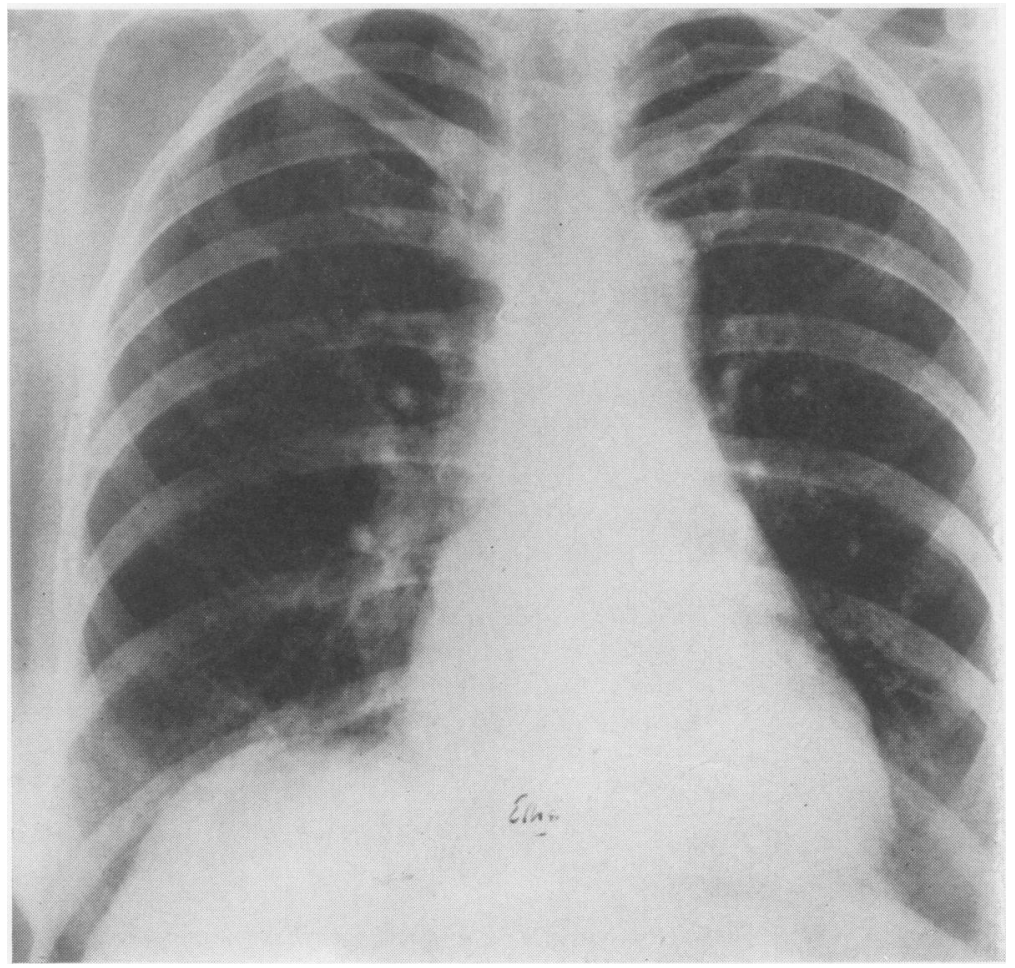

FI(i. 19. Patient 5. Post-operative chest radiograph shows reduction in size of the left atrium and ventricle.

T A B L E I CLINICAL PRESENTATION

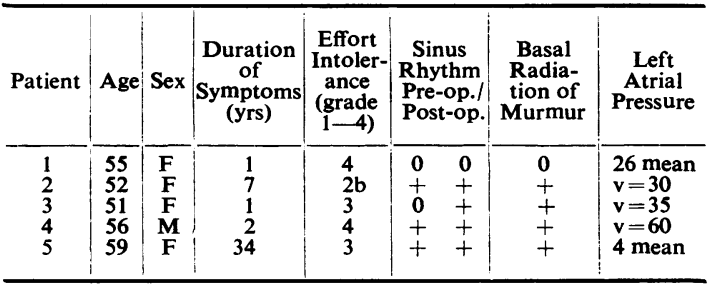

The operative findings are shown in Table II. In all five patients a thrill was palpable with a finger in the right atrium on the interatrial septum where the jet impinged as it was directed forward by the prolapsing hood of posterior cusp. This finding is in contrast to that in rheumatic mitral incompetence, where the thrill is maximal in the posterior part of the left atrium. In no case was the mitral valve found to be affected by rheumatic or bacterial endocarditis or papillary muscle infarction, and cusp mobility was normal. The abnormally redundant type of valve found in patient
5 was an example of an increasingly well recognized condition (Edwards and Burchell, 1958; Berghuis et al., 1964 ; Gerein et al., 1965 ; Barlow and Bosman, 1966 ; Stannard et al., 1967). The other four had normal or slightly enlarged mural cusps with chordal detachment and prolapse of the centre of the cusp.

The findings at follow-up are summarized in Table III. The mean period of follow-up was 11 months (6-16 months) and is thus over three months in all cases, beyond which regurgitation is

T A B L E II OPERATIVE FINDINGS

\begin{tabular}{|c|c|c|c|c|c|c|}
\hline \multirow{2}{*}{ Patient } & \multicolumn{2}{|c|}{$\begin{array}{l}\text { Left Atrial } \\
\text { Pressure }\end{array}$} & \multicolumn{2}{|c|}{ Valve } & \multirow{2}{*}{$\begin{array}{c}\text { Thrill } \\
\text { Palpable } \\
\text { on } \\
\text { Atrial } \\
\text { Septum }\end{array}$} & \multirow{2}{*}{$\begin{array}{l}\text { Evidence } \\
\text { of } \\
\text { Rheumatic } \\
\text { Aetiology }\end{array}$} \\
\hline & Pre-op. & Post-op & Mobility & $\begin{array}{c}\text { Calcifica- } \\
\text { tion }\end{array}$ & & \\
\hline $\begin{array}{l}1 \\
2 \\
3\end{array}$ & \begin{tabular}{l|}
$6 \overline{60 / 11}$ \\
$17 / 15$ \\
$45 / 9$ \\
\end{tabular} & $\begin{array}{c}\overline{25 / 15} \\
13 / 6 \\
3 / 1 \\
-\end{array}$ & $\begin{array}{l}\text { Normal } \\
\text { Normal } \\
\text { Normal } \\
\text { Normal } \\
\text { Re- } \\
\text { dundant }\end{array}$ & $\begin{array}{l}\mathbf{0} \\
\mathbf{0} \\
\mathbf{0} \\
\mathbf{0} \\
\mathbf{0}\end{array}$ & $\begin{array}{l}+ \\
+ \\
+ \\
+ \\
+\end{array}$ & $\begin{array}{l}0 \\
0 \\
0 \\
0 \\
0\end{array}$ \\
\hline
\end{tabular}


T A B LE III

FINDINGS AT FOLLOW-UP

\begin{tabular}{c|c|c|c|c|c}
\hline Patient & $\begin{array}{c}\text { Time } \\
\text { after } \\
\text { Operation }\end{array}$ & $\begin{array}{c}\text { Systolic } \\
\text { Murmur } \\
\text { (grade 1-4) }\end{array}$ & $\begin{array}{c}\text { Sinus } \\
\text { Rhythm }\end{array}$ & $\begin{array}{c}\text { Reduction in } \\
\text { Cardiothoracic } \\
\text { Ratio (\%) }\end{array}$ & Embolism \\
\hline 1 & 10 days & 0 & 0 & - & Air \\
2 & 15 months & 2 & + & 10 & 0 \\
3 & 13 months & 0 & + & 9 & 0 \\
4 & 12 months & 0 & + & 10 & 0 \\
5 & 6 months & 1 & + & 11 & 0 \\
\hline
\end{tabular}

said not to develop (Hessel, Kennedy, and Merendino, 1966). The four survivors were in sinus rhythm and either free of murmur (2) or with a soft systolic murmur with no evidence of haemodynamically significant mitral incompetence (2). Left ventricular hypertrophy was absent or diminished, and diminution in the size of the heart was observed radiologically. No patient was on anticoagulants after the immediate postoperative period and there had been no embolic episode. Apart from the first patient, who died of air embolism when this problem in this type of operation was not fully appreciated, the remarkably smooth post-operative course has been followed by a normal life in all the patients.

\section{DISCUSSION}

In recent years replacement of a mitral valve with a prosthesis has been advocated for all patients undergoing surgery for chordal abnormalities (Raftery et al., 1966; Sanders et al., 1967; Sanders, Scannell, Harthorne, and Austen, 1965). In nearly half $(26 / 53)$ of the patients from these series the ruptured chordae tendineae responsible for the mitral incompetence were of the anterior (aortic) cusp. Valve replacement is usually necessary for anterior cusp prolapse, but this does not justify its recommendation for surgery of all abnormalities of the chordae tendineae. Valvoplasty can be shown to be an improvement on prosthetic valve replacement for posterior (mural) chordal abnormalities, in respect of operative mortality, morbidity, and long-term correction of mitral incompetence.

The operative mortality of prosthetic valve replacement for ruptured chordae tendineae is lower than that for rheumatic disorders (Raftery et al., 1966) but is higher than that associated with conservative measures (Björk and Malers, 1964a, b). In one year no patient was lost from conservative surgery at the Mayo Clinic but $13.5 \%$ from prosthetic valve replacement (Ellis, Callahan, McGoon, and Kirklin, 1965). This is in accord with our experience.
The morbidity and late mortality associated with prosthetic valves are the results of three groups of complications: those due to the valve being of artificial material (embolism and infection) (Herr, Starr, McCord, and Wood, 1965), those due to a degree of obstruction by the prosthesis (back-pressure in the left atrium) (Morrow, Clark, Harrison, and Braunwald, 1964), and those caused by technical failure in inserting the valve (leakage, ventricular irritation, outflow tract obstruction, and hindrance of movement of the ball by the ventricular wall (Morrow et al., 1964)).

Thrombosis and embolism did not occur after conservative surgery for ruptured chordae tendineae in the Mayo Clinic series or in this one, though anticoagulants were used only during the hospital admission (Ellis et al., 1965). After prosthetic replacement despite anticoagulant therapy, $42 \%$ of patients may have emboli (Herr et al., 1965), a rate of 44 embolic episodes in 1,150 patient months, or one every 26 patient-months. Without anticoagulants the embolic risk associated with prostheses is one embolic episode per 16 patient-months (Yeh, Anabtawi, Cornett, and Ellison, 1967).

Infection after conservative surgery is also rare. No case of bacterial endocarditis occurred in our series or the others (Hessel et al., 1966; Ellis et al., 1965). A $10 \%$ incidence of infection on prosthetic mitral valves can occur (Morrow et al., 1964), although intensified preventive measures can make infection much less frequent (Herr et al., 1965).

Prosthetic valves produce relative obstruction to left atrial emptying, especially during exercise, when gradients of up to $14 \mathrm{~mm}$. $\mathrm{Hg}$ may develop (Morrow et al., 1964): With conservative surgery, though the annulus is reduced, the effective orifice between the cusps is not diminished enough to cause significant obstruction. No post-operative intracardiac pressures were measured in this series, but in those in which they have been measured, no gradient has been found across the mitral valve after conservative correction of pure mitral incompetence either at rest or during exercise (Björk and Malers, 1964a). Though two of the five patients in this series have developed a systolic murmur, neither has clinical evidence of haemodynamically significant mitral incompetence. Although other series show a similar incidence of post-operative murmurs, the $92 \%$ of good results observed in eight centres suggests that they are of little importance (Hessel et al., 1966). Leakage past the annulus of prosthetic valves is 
also fairly common, eight of 102 in one series, and when present is usually sufficiently significant to require correction (Rockoff, Ross, Oldham, Mason, Morrow, and Braunwald, 1966). Postoperative morbidity related to a prosthetic valve being of the wrong size, or in the wrong position, irritating the ventricular myocardium, or obstructing the outflow tract of the left ventricle can obviously never follow valvoplasty.

The longer term results are also good following plication of the posterior cusp. At follow-up our patients showed maintained improvement over 45 patient-months. Hessel et al. (1966) report that five out of six of their series of patients were restored to a normal, or near normal, life, four having normal exercise tolerance tests. Ball valve mitral prostheses have a gradient across them at high flow rates, and in one series the mean working capacity of the survivors rose from 310 to $380 \mathrm{kpm} / \mathrm{min}$. only (Björk and Malers, 1964b), while an average rise from 217 to $500 \mathrm{kpm} / \mathrm{min}$. was reported after valvoplasty (Björk and Malers, 1964a). The average cardiac diameter after valvoplasty in Hessel's series was reduced by $18 \%$, in Björk's series by $17 \%$, and in this series by $10 \%$, while the reduction in heart size after total valve replacement was 3.6\% (Hessel et al., 1966 ; Björk and Malers, 1964a). The evidence available thus suggests that conservative surgery is the best treatment for rupture of posterior chordae tendineae. No other type of valvoplasty for this lesion has achieved the reputation of the McGoon procedure, though several have been attemptedleaflet bolstering (Ellis, Brandenburg, Callahan, and Marshall, 1959), Teflon chordal replacement (Morris et al., 1964), chordal resuture and annuloplasty (Kay, Egerton, and Zubiate, 1961 ; Wooler, Nixon, Grimshaw, and Watson, 1962), and cusp excision (Hessel et al., 1966).

The advantages of the McGoon procedure are simplicity, preservation of all the working subvalvar apparatus, and the absence of prosthetic material. Annuloplasty alone is not successful for this condition (Morris et al., 1964) but is necessary as an adjunct to any alteration of the cusp, though its form may vary (Gerbode et al., 1966 ; Kay, Tsiji, and Redington, 1965 ; Kay, Magidson, and Meihaus, 1962). Plication of the ring and atrial wall in continuity offers support to the suture line on the cusp as well as the necessary reduction of size of the annulus to compensate for loss of effective cusp area. Simplicity of performance, low mortality rate, ease of post-operative management, and the high percentage of good immediate and long-term results make the modi- $\bar{C}$ fied McGoon procedure the operation of choice for rupture of posterior chordae tendineae or $\frac{\bar{S}}{7}$ redundancy of the posterior cusp.

\section{REFERENCES}

Barlow, J. B., and Bosman, C. K. (1966). Aneurysmal protrusion of the posterior leaflet of the mitral valve. Amer. Heart J., 71, 166.

Berghuis, J., Kirklin, J. W., Edwards, J. E., and Titus, J. L. (1964). The surgical anatomy of isolated congenital mitral insufficiency. J. thorac. cardiovasc. Surg., 47, 791.

Björk, V. O., and Malers, E. (1964a). Annuloplastic procedures for mitral insufficiency: Late results. Ibid., 48, 251. 48, 625 .

Edwards, J. E., and Burchell, H. B. (1958). Pathologic anatomy of mitral insufficiency. Proc. Mayo Clin., 33, 497.

Ellis, F. H., Callahan, J. A., McGoon, D. C., and Kirklin, J. W. (1965). Results of open operation for acquired mitral-valve disease. New Engl. J. Med., 272, 869.

- Brandenburg, R. O., Callahan, J. A., and Marshall, H. W. (1959). Open heart surgery for acquired mitral insufficiency. Arch. Surg., 79. 222 .

Gerbode, F., Kerth, W. J., Kelly, J. J., and Selzer, A. (1966). The surgical correction of mitral insufficiency due to ruptured chordae tendineae. Bull. Soc. int. Chir., 25, 483.

Gerein, A. N., Gourlay, R. H., and Kavanagh-Gray D. (1965). Open-heart surgery for mitral valve disease. Canad. med. Ass. J., $\infty$ 93,643

Herr, R., Starr, A., McCord, C. W., and Wood, J. A. (1965). Special problems following valve replacement: embolus, leak, infection, red cell damage. Ann. thorac. Surg., 1, 403.

Hessel, E. A., Kennedy, J. W., and Merendino, K. A. (1966). A reappraisal of non-prosthetic reconstructive surgery for mitral regurgitation based on an analysis of early and late results. $J$. thorac. cardiovasc. Surg., 52, 193.

Kay, J. H., Egerton, W. S., and Zubiate, P. (1961). The surgical treat- $\varrho$ ment of mitral insufficiency and combined mitral stenosis and $\overline{\bar{O}}$ insufficiency with use of the heart-lung machine. Surgery, 50, 67 . - Magidson, O., and Meihaus, J. E. (1962). The surgical treatment $\exists$ of mitral insufficiency and combined mitral stenosis and insufficiency using the heart-lung machine. Amer.J. Cardiol., 9, 300.

- Tsuji, H. K., and Redington, J. V. (1965). The surgical treatment of mitral insufficiency associated with torn chordae tendineae. Ann. thorac. Surg., 1, 269.

McGoon, D. C. (1960). Repair of mitral insufficiency due to ruptured chordae tendineae. J. thorac. cardiovasc. Surg., 39, 357.

Morrow, A. G., Clark, W. D., Harrison, D. C., and Braunwald, E. (1964). Prosthetic replacement of the mitral valve-operative methods and the results of preoperative and postoperative hemodynamic assessments. Circulation, 29-30, Suppl. I (April), p. 2.

Morris, J. D., Penner, D. A., and Brandt, R. L., (1964). Surgical correction of ruptured chordae tendineae. J. thorac. cardiovasc. Surg., 48, 772.

Raftery, E. B., Oakley, C. M., and Goodwin, J. F. (1966). Acute subvalvar mitral incompetence. Lancet, 2, 360.

Rockoff, S. D., Ross, J., Oldham, N. N., Mason, D. T., Morrow, $\frac{I}{O}$ A. G., and Braunwald, E. (1966). Ventriculo-atrial regurgitation following prosthetic replacement of the mitral valve. Amer. J. Cardiol., 17, 817.

Sanders, C. A., Austen, W. G., Harthorne, J. W., Dinsmore, R. E., S and Scannell, J. G. (1967). Diagnosis and surgical treatment of $N$ mitral regurgitation secondary to ruptured chordae tendineae. New Engl. J. Med., 276, 943.

- Scannell, J. G., Harthorne, J. W., and Austen, W. G. (1965). $\omega$ Severe mitral regurgitation secondary to ruptured chordae ${ }^{O}$ tendineae. Circulation, 31, 506.

Stannard, M., Sloman, J. G., Hare, W. S. C., and Goble, A. J. (1967). Prolapse of the posterior leaflet of the mitral valve. A clinical, $\mathbb{D}$ familial, and cineangiographic study. Brit. med.J., 3, 71 .

Wooler, G. H., Nixon, P. G. F., Grimshaw, V. A., and Watson, D. A. (1962). Experiences with the repair of the mitral valve in mitral incompetence, Thorax 17, 49 .

Yeh, T. J., Anabtawi, I. N., Cornett, V. E., and Ellison, R. G. (1967). Influence of rhythm and anticoagulation on the incidence of embolization associated with Starr-Edwards prostheses. Circulation, 35-36, Suppl. I, p. 77. 